\title{
A MICROAGGLUTINATION TEST FOR YERSINIA ENTEROCOLITICA INFECTION: RECOGNITION OF MULTIPLE SEROTYPES IN EXPERIMENTS WITH STAINED SUSPENSIONS OF SEROTYPE O 5,27
}

\author{
I. D. Ricciardi*, A. D. Pearson†, W. G. Suckling $\dagger$ and C. Klein $\dagger$ \\ *Institute of Microbiology, Federal University of Rio de Janeiro, Brazil, and \\ $\dagger$ Department of Microbiology, Southampton University, Tremona Road, \\ Southampton SO9 $4 X Y$
}

IN published reports, human beings infected with Yersinia enterocolitica usually had either abdominal pain or diarrhoea as their presenting symptom. During a 1-year study in Sweden, $Y$. enterocolitica was isolated from $22(3.8 \%)$ of 581 patients with appendicitis and from 16 $(5.6 \%)$ of 284 patients with abdominal pain in whom appendicitis was suspected (Niléhn, 1969). Investigation of these patients showed that positive cultures correlated with the presence of antibodies to serotype 3 while few of the culture-negative group had agglutinins. The serological diagnosis of $Y$. enterocolitica infection is usually made by carrying out tube agglutination tests to detect type-specific antibodies. Two schemes of antigenic classification of $Y$. enterocolitica are in use, namely (1) the Winblad scheme (Winblad, 1968) which comprises serotypes $\mathrm{O} 1$ to $\mathrm{O} 9$, and (2) Wauters' classification (Wauters et al., 1972) which extends the $\mathrm{O}$ serotypes to 34 . Because the detection of antibodies to all of these serotypes would require many tests, the search is usually limited to tests for antibodies to commonly recognised serotypes, for example O3 and O9 in Europe (Niléhn, 1969; Mollaret, 1971). This practice, of course, fails to detect clinical infection with a wide range of less common serotypes and non-typable strains (Niléhn, 1969; Mollaret, 1971; Aldová and Lím, 1974; Kapperud. 1977). A test based on an antigen common to all types would therefore be useful.

In attempting to assess the importance of strains other than those of the common serotypes Lysy and Knapp (1973) have used a haemagglutination test, but this has limited specificity (Maeland and Digranes, 1975a and $b$ ); and Carlsson, Hurvell and Lindberg (1976) have devised an experimental enzyme-linked immunosorbent assay.

This paper describes a simple microagglutination test, with a stained antigen preparation that appears to possess a species antigen that is specific.

\section{MATERIALS AND METHODS}

Bacterial strains. The following serotypes (Wauters' scheme) of $Y$. enterocolitica were used: O1 (O1, 2a, 3-I.P. 135); O2 (O2a, 2b, 3-I.P. 178); O4 (O4,32-I.P. 96); O5 (I.P. 123); O5 (O5,27-I.P. 885); O6 (O6,30-I.P. 102), and O7 (O7,8-I.P. 106), kindly supplied by Professor G. Wauters (Ecole Santé Publique, Brussels); serotypes O3 (I.P. 134) and O9 (I.P. 383) supplied by Dr N. S. Mair (Public Health Laboratory, Leicester, England); and serotype 08 (strain W. A.; NCTC10938), derived from a recent American isolate and virulent for mice (Carter, 1975).

Antigens for tube agglutination tests. Strains were grown on Nutrient Agar (CM-3;

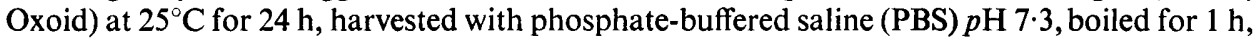
washed twice with PBS and then adjusted in a Unicam SP1800 spectrophotometer to an optical density (OD) of 0.3 at $540 \mathrm{~nm}$.

Antigens for microtitre plate-agglutination tests. Strains were grown and harvested as above. Before boiling, the suspension was stained with $2: 3: 5$ triphenyl-tetrazolium chloride (TTC, British Drug Houses, Poole, England) at a final concentration of $0.2 \% \mathrm{w} / \mathrm{v}$. After incubation for $1 \mathrm{~h}$ at $25^{\circ} \mathrm{C}$ the suspension was boiled for $1 \mathrm{~h}$, washed three times with PBS, resuspended in PBS containing 1\% v/v glycerol and used at an OD of 1.6 at $680 \mathrm{~nm}$.

Received 1 Nov. 1977; accepted 17 Feb. 1978.

J. MED. MICROBIOL.-VOL. 11 (1978) 
Antisera. Reference antisera prepared in rabbits against Wauters' serotypes $\mathrm{O} 1$ to $\mathrm{O} 9$ of $Y$. enterocolitica were received from Professor Wauters. Additional antisera to serotypes $\mathrm{O} 3$ and 09 were prepared by immunising rabbits with heat-killed organisms in Freund's incomplete adjuvant; a total of $2.5 \mathrm{ml}$ of a suspension containing $10^{8}$ organisms per $\mathrm{ml}$ was injected subcutaneously in four doses over a period of 4 weeks and the antisera were collected during the 5th week. In addition, antisera to serotypes O3, O8 (strain WA) and O9 were obtained by inoculating Porton white mice intraperitoneally with a single dose containing $10^{7}$ live organisms. Human sera from patients infected with serotype $\mathrm{O} 3$ were received from $\mathrm{Dr}$ N. S. Mair. Sera were examined from two additional groups of patients, namely (1) patients with fever of undetermined origin lacking antibodies to Brucella abortus and Francisella tularensis (with controls from patients with positive serological tests for $F$. tularensis), and (2) patients (mainly children) with abdominal pain.

Antisera to Brucella abortus, Vibrio cholerae, salmonellae (poly $\mathrm{O}$, poly $\mathrm{H}$ and $\mathrm{Vi}$ ), and Escherichia coli (poly I-O26, O55, O111, O119, O126; poly II-O86, O114, 0125, O127, O128 and poly III-O18, O44, O112a, O124a c, O142) were kindly supplied by the Standards Laboratory, Central Public Health Laboratory, Colindale. Antisera to Yersinia pseudotuberculosis serotypes 1 to 6 were supplied by Dr N. S. Mair.

Tube agglutination tests. These were performed as described by Winblad (1975), but incubating at $37^{\circ} \mathrm{C}$. Sera were diluted in PBS starting at a dilution of 1 in 10; the end-point was taken as the highest dilution producing naked-eye agglutination.

Microtitre plate-agglutination tests. These were carried out in Microtiter Plates, Model 1S-MRC-96 (Linbro Chemical Company, New Haven, Conn., USA). A dilution of serum of 1 in 2 or 1 in 10 was used. The cell suspension settled rapidly but reproducible end-points were observed only after overnight incubation at $37^{\circ} \mathrm{C}$. The end-point was taken as the highest dilution of serum giving a mat of stained antigen. End-points were affected also by antigen concentration; the effect of this was investigated by testing suspensions of optical densities of 1.4, 1.6 and 2.0 against rabbit antiserum. Reproducible results could not be obtained with the antigen at OD 1.4. Titres of 320 and 1280 were obtained with antigen at OD values of 1.6 and 2.0 respectively. Antigen at OD 1.6 gave the clearest endpoints and was chosen for all further tests.

\section{RESULTS}

In experiments with human, rabbit and mouse sera the sensitivities of microtitre plate and tube agglutination tests were similar (table I), the slight variations observed being due to differences in the starting dilutions. When the type specificity of suspensions of serotypes $\mathrm{O} 3$ and 09 was tested in microtitre plates against homologous and heterologous antisera, strong cross-reactivity was observed with both TTC-stained suspensions, whereas unstained suspensions reacted specifically. TTC thus affected the specificity of the antigen in both the microtitre plate and tube agglutination tests (table II).

As a result of these findings, TTC-stained suspensions of serotypes 01 to 09 were tested in a "chessboard" pattern against antisera to a range of $Y$. enterocolitica serotypes; all cross-reacted. Results are presented in table III for the four serotypes most frequently associated with human infection, namely: $03 ; 05,27 ; 08 ; 09$. The TTC-stained suspensions of serotype 05,27 consistently agglutinated with heterologous sera. In table IV the results obtained when TTC-stained suspensions of serotype 05,27 were tested in microtitre plates against sera from mice infected with serotypes 03,08 or 09 are compared with the results obtained by testing the same sera against their homologous antigen by both the tube and microtitre plate methods. It will be seen that the reactivity of TTC-stained suspensions of serotype 05,27 differed little from that of the individual homologous antigens.

The cross-reactivity of TTC-stained antigens in microtitre plate tests was further investigated by testing them against antisera to B.abortus, $V$. cholerae, salmonellae (poly $\mathrm{O}$, poly $\mathrm{H}$ and $\mathrm{Vi}$ ), Shigella flexneri, Shigella sonnei, E. coli (polyvalent sera I, II and III) and Y. pseudotuberculosis serotypes 1 to 6 . Cross-reactions were not observed with TTC-stained suspensions of serotype O3. TTC-stained suspensions of serotype O9 reacted with B. abortus to a titre of 128 , and with antiserum to $V$. cholerae to a titre of 16 . These cross-reactions are similar to 
TABLE I

Titres obtained in tube and microtitre-plate agglutination tests of sera from patients and experimentally-infected animals

\begin{tabular}{|c|c|c|}
\hline \multirow{2}{*}{$\begin{array}{c}\text { Serum source } \\
\text { (and infecting serotype } \\
\text { of } Y . \text { enterocolitica) }\end{array}$} & \multicolumn{2}{|c|}{ Titres* obtained in } \\
\hline & tube test & $\begin{array}{l}\text { microtitre } \\
\text { plate test }\end{array}$ \\
\hline Patient 1 & 160 & 128 \\
\hline Patient 2 & 80 & 64 \\
\hline $\begin{array}{c}\text { Rabbit } 1 \\
\text { (O3) }\end{array}$ & 640 & 256 \\
\hline$\underset{\text { (O9) }}{\text { Rabbit } 2}$ & 1280 & 512 \\
\hline $\begin{array}{l}\text { Mouse } 1 \\
\text { (O3) }\end{array}$ & 40 & 32 \\
\hline $\begin{array}{c}\text { Mouse } 2 \\
\text { (O3) }\end{array}$ & 40 & 40 \\
\hline $\begin{array}{c}\text { Mouse } 3 \\
\text { (O3) }\end{array}$ & 40 & 40 \\
\hline $\begin{array}{l}\text { Mouse } 4 \\
\text { (O8) }\end{array}$ & 40 & 16 \\
\hline $\begin{array}{l}\text { Mouse } 5 \\
\text { (O9) }\end{array}$ & 80 & 64 \\
\hline $\begin{array}{c}\text { Mouse } 6 \\
\text { (09) }\end{array}$ & 320 & 160 \\
\hline
\end{tabular}

* The titres are the highest obtained against homologous antigen.

TABLE II

Effect of TTC staining on the specificity of antigen in tube agglutination tests

\begin{tabular}{|c|c|c|c|c|}
\hline \multirow{3}{*}{$\begin{array}{l}\text { Rabbit } \\
\text { antiserum to } \\
\text { serotype }\end{array}$} & \multicolumn{4}{|c|}{ Titre of rabbit antiserum as shown by } \\
\hline & \multicolumn{2}{|c|}{$\begin{array}{l}\text { stained } \\
\text { antigen }\end{array}$} & \multicolumn{2}{|c|}{$\begin{array}{l}\text { unstained } \\
\text { antigen }\end{array}$} \\
\hline & 03 & 09 & O3 & $\overrightarrow{09}$ \\
\hline $\mathrm{O} 3$ & 640 & 320 & 640 & 40 \\
\hline 09 & 320 & 1280 & 40 & 1280 \\
\hline
\end{tabular}

those described by Ahvonen, Jansson and Aho (1969) and Barua and Watanabe (1972). Suspensions of serotype 05,27 stained with TTC reacted with antisera to $Y$. pseudotuberculosis, serotypes $1,3,5$ and 6 , but the titres did not exceed 32 .

The reactivity of TTC-stained suspensions of serotype 05,27 with human sera was assessed in microtitre plate tests with sera from three groups of individuals. The first group comprised 261 patients with pyrexia of undetermined origin whose sera lacked antibodies to brucella and $F$. tularensis. The second group comprised 10 people whose sera contained agglutinins for $F$. tularensis; none of these sera agglutinated TTC-stained suspensions of serotype 05,27 at a dilution of 1 in 4 . The third group, from which 190 sera were tested, 


\section{TABLE III}

Cross-reactivity of TTC-stained antigen suspensions of four serotypes with rabbit antisera to serotypes 01 to 09 of Yersinia enterocolitica

\begin{tabular}{|c|c|c|c|c|c|c|c|c|c|c|}
\hline \multirow{2}{*}{$\begin{array}{l}\text { Antigen } \\
\text { suspension of } \\
\text { serotype }\end{array}$} & \multicolumn{10}{|c|}{ Titre demonstrated in antiserum to serotype } \\
\hline & $01,2 \mathrm{a}, 3$ & $\mathrm{O} 2 \mathrm{a}, 2 \mathrm{~b}, 3$ & $\mathbf{0 3}$ & 04,32 & 05 & 05,27 & 06,30 & 07,8 & 08 & 09 \\
\hline O3 & 32 & 1024 & 1024 & 64 & 256 & 2048 & 64 & 32 & 256 & 1024 \\
\hline 05,27 & 128 & 128 & 128 & 128 & 256 & 4096 & 64 & 32 & 128 & 2410 \\
\hline 08 & 16 & 64 & 512 & 16 & 4 & 4096 & 128 & 512 & 512 & 256 \\
\hline 09 & 64 & 64 & 512 & 32 & 32 & 4096 & 128 & 16 & 256 & 2048 \\
\hline
\end{tabular}

\section{TABLE IV}

Titres of mouse sera tested by tube agglutination against unstained homologous antigens and by microtitre plate agglutination against homologous and 05,27 TTC-stained antigens

Serotypes of $Y$. enterocolitica against which antisera were produced (in mice no. 1-6)
Titres demonstrated in mouse antisera by

$\overbrace{\begin{array}{c}\text { tube test with unstained } \\ \text { homologous antigen }\end{array}}^{\overbrace{\begin{array}{c}\text { homologous } \\ \text { antigen }\end{array}}^{\text {microtitre plate test with }} \begin{array}{c}\text { O5,27 } \\ \text { antigen }\end{array}}$

$\begin{array}{rrr}40 & 32 & 8 \\ 40 & 40 & 16 \\ 40 & 40 & 16 \\ 40 & 16 & 16 \\ 80 & 64 & 32 \\ 20 & 160 & 128\end{array}$

consisted of patients, mostly children, admitted to hospital with abdominal pain. Sera from 10 of these patients agglutinated TTC-stained suspensions of serotype 05,27 to a titre of 8; one patient had a titre of 64 . Two of these 10 sera had higher titres with other antigens: one had a titre of 16 with TTC-stained antigen of serotype 03, and a second had a titre of 32 with TTC-stained antigen of serotype 09 .

\section{Discussion}

In the experiments described above the specificity and cross-reactivity of suspensions of $Y$. enterocolitica serotype 05,27 stained with TTC were established by testing sera from experimentally infected animals. The results also showed that sera from patients from whom $Y$. enterocolitica had been isolated gave titres that were similar in both microtitre-plate and tube-agglutination tests. Non-specific agglutination was not detected in tests of sera from 261 patients with pyrexia of undetermined origin, nor was cross-reactivity demonstrated when TTC-stained suspensions of serotype 05,27 were tested against antisera to organisms of five 
other genera. However, TTC-stained suspensions of serotype 05,27 reacted almost as well as the homologous antigens with antisera to other serotypes of $Y$. enterocolitica. Thus, in these experiments, microtitre plate-agglutination tests with TTC-stained suspensions of serotype 05,27 appeared to offer a method for detecting antibodies to a wide range of $Y$. enterocolitica serotypes that was more satisfactory and simple than multiple tube agglutination tests.

To detect antibody to Y. enterocolitica Lysy and Knapp (1973) have used a haemagglutination test with a supernate of an autoclaved bacterial suspension as antigen. This preparation may contain common enterobacterial antigen (CEA), thus explaining the lack of specificity of haemagglutination tests reported by Maeland and Digranes (1975a and $b$ ). Recently Makela and Mayer (1976) have described a technique for extracting lipopolysaccharide antigens free from CEA; this technique might improve the specificity of $Y$. enterocolitica antigens in haemagglutination tests.

It is not clear why suspensions of $Y$. enterocolitica, when stained with TTC, should have altered antigenic specificity. TTC has been used to stain brucella antigens and its use as an antigen stain in microtitre plate tests for clinical, serological and epidemiological investigations of brucellosis is well established (Mello and Mello, 1969; Ricciardi et al., 1976). To our knowledge antigen modification has not been recognised in TTC-stained brucella preparations. An understanding of the action of TTC on the bacterial cell might lead to the identification of a species-specific and possibly even a genus-specific diagnostic antigen. Further, it is possible that an antiserum to TTC-stained suspensions of serotype O5,27 would be of use in the detection of biochemically aberrant strains of $Y$. enterocolitica.

Evaluation is now needed of the usefulness of TTC-stained suspensions of serotype O5,27 as the antigen in a species-specific serological test for antibodies to $Y$. enterocolitica by testing many more sera from patients from whom different serotypes of $Y$. enterocolitica have been isolated. Such sera are not currently available to us.

\section{SUMMARY}

When suspensions of Yersinia enterocolitica were stained with triphenyl-tetrazolium chloride (TTC) their antigenic specificity, as determined by tube and microtitre-plate agglutination tests, was altered.

Thus, a TTC-stained suspension of serotype 05,27 detected antibodies to nine $\mathrm{O}$ serotypes of $Y$. enterocolitica in sera from experimentally infected animals but did not cross-react with antisera to organisms of five other unrelated genera including Brucella. The same suspension did, however, cross-react weakly with antisera to four serotypes of Yersinia pseudotuberculosis.

The value of this antigen preparation in detecting antibodies to the wide range of $Y$. enterocolitica serotypes likely to cause infection in man should now be assessed.

\section{REFERENCES}

AldovÁ, E. AND Lím, D. 1974. Yersinia enterocolitica in small rodents. Communication 1: pilot study in two wild-life areas. Zentbl. Bakt. ParasitKde, I. Abt. Orig. A., 226, 491.

AhVonen, P., JANSSON, E. AND AHo, K. 1969. Marked cross-agglutination between Brucellae and a subtype of Yersinia enterocolitica. Acta. path. microbiol. scand., 75, 291.

Barua, D. AND Watanabe, Y. 1972. Vibriocidal antibodies induced by Yersinia enterocolitica serotype IX. J. Hyg., Camb., 70, 161.

Carlsson, H. E., Hurvell, B. and LindberG, A. A. 1976. Enzyme linked immunosorbent assay (Elisa) for titration of antibodies against Brucella abortus and Yersinia enterocolitica. Acta path. microbiol. scand., Sect. C, 84, 168.

CARTER, P. B. 1975. Animal model: oral Yersinia enterocolitica infection of mice. Am.J. Path., 81, 703.

KAPPERUD, G. 1977. Yersinia enterocolitica and Yersinia like microbes isolated from mammals and water in Norway and Denmark. Acta path. microbiol. scand., Sect. B, 85, 129. 
LYSY, J. AND KNAPP, W. 1973. Serological studies with $Y$. enterocolitica. In Contributions to microbiology and immunology, edited by S. Winblad, Basel, vol. 2, p. 42.

Maeland, J. A. ANd Digranes, A. 1975a. Common enterobacterial antigen in Yersinia enterocolitica. Acta path. microbiol. scand., Sect. B, 83, 382.

Maeland, J. A. ANd Digranes, A. 1975b. Human serum antibodies against heat stable antigens from Yersinia enterocolitica. Acta path. microbiol. scand., Sect. B, 83, 451.

MAKela, P. H. AND MaYeR, H. 1976. Enterobacterial common antigen. Bact. Rev., 40, 591.

Mello, M. T. DE ANd Mello, A. M. DE. 1969. Microtécnicas serológicas para el diagnostico de peste, brucelosis y leptospirosis. Boln Of. sanit. pan-am., 67, 300.

MollareT, H. H. 1971. L'infection humaine à Yersinia enterocolitica en 1970, à la lumière de 642 cas récents. Aspects cliniques et perspectives. Path. Biol., Paris, 19, 189.

NiLÉHN, B. 1969. Studies on Yersinia enterocolitica with special reference to bacterial diagnosis and occurrence in human acute enteric disease. Acta path. microbiol. scand., Suppl. 206.

Ricciardi, I. D., Nunes, M. P., Andrade, C. M. and Silva, A. G. 1976. Anti Brucella agglutinins in bats and Callithrix monkeys. J. wildlife Dis., 12, 52.

Wauters, G., LeMinor, L., Chalon, A. M. and Lassen, J. 1972. Supplement au Schema antigénique de Yersinia enterocolitica. Annls Inst. Pasteur, Paris, 122, 951.

Winblad, S. 1968. Studies on O-antigen factors of Yersinia enterocolitica. In Proc. 20th Int. Sympos. Pseudotuberculosis, Symposia on Immunological Standardisation, vol. 9, Basel, p. 337.

WINBLAD, S. 1975. Arthritis associated with Yersinia enterocolitica infections. Scand. J. infect. Dis., 7, 191. 